\title{
BCR/ABL-1-Positive Myeloproliferative Neoplasm Presenting with Isolated Remarkable Thrombocytosis with Atypical Clinicopathological Features: Discussion from Management Point of View
}

Dina Sameh Soliman ${ }^{1,3,4 *}$, Mohammad A Abdulla ${ }^{1}$, Ahmad Al Sabbagh ${ }^{1,4}$, Susanna Akiki ${ }^{1}$, Feryal Ibrahim ${ }^{1}$, Afraa Mustafa² and Mohamed Yassin 2,4

${ }^{1}$ Department of Laboratory Medicine and Pathology, National Center for Cancer Care and Research, Hamad Medical Corporation, Doha, Qatar ${ }^{2}$ Department of Hematology and Medical Oncology, National Center for Cancer Care and Research, Hamad Medical Corporation, Doha, Qatar ${ }^{3}$ Department of Clinical Pathology, National Cancer Institute, Cairo University, Cairo, Egypt

${ }^{4}$ Department of Clinical Pathology, Weill Cornell Medical College, Qatar

\begin{abstract}
Chronic Myeloid Leukaemia can rarely present in essential Thrombocythaemia-like picture. Apart from the genetic defining marker (BCR-ABL fusion), these cases lack almost all typical features of CML.

Here, we highlight the response of these patients to different therapeutic approaches and to emphasize that although the proliferation is solely limited to the platelets; this group of patients did not show any response except after initiation of Tyrosine kinase inhibitors which highpoints the essentiality of excluding CML by performing $B C R /$ $A B L-1$ in all cases with features of myeloproliferative neoplasms in order to avoid delayed management and adverse outcome. Apparently, many hematologists have not been persuaded to always test for $B C R / A B L-1$ when there are no features suggesting $\mathrm{CML}$.
\end{abstract}

Unlike what was previously reported, upon literature review, we found no significant difference in disease prognosis in this group of patients compared to classic CML, provided TKI was started early in disease course.

Keywords: Chronic myeloid leukaemia; Isolated thrombocytosis; $\mathrm{Ph}$ positive thrombocythaemia; Tyrosine kinase inhibitor

Abbreviations: MPN: Myeloproliferative Neoplasms; CML: Chronic Myeloid leukemia; PB: Peripheral Blood; BM: Bone Marrow; CBC: Complete Blood Count; WBCs: White Blood Cells; Hb: Hemoglobin; PLts: Platelets; ECG: Electrocardiogram; ET: Essential Thrombocythaemia; M/E: Myeloid/Erythroid; TKI: Tyrosine Kinase Inhibitor; CAD: Coronary Artery Disease; OR: Optimal Response; Hyper: Hypercellular BM; N: Normal; N/P: Not Provided; VC: Vascular Complications; US: Ultrasound; E: Physical Exam; MI: Myocardial Infarction; PE: Pulmonary Embolism; Allo SCT: Allogenic Stem Cell Transplant.

\section{Introduction}

Although myeloproliferative neoplasms (MPN) are an overlapping group of myeloid neoplasms that may share a common pathogenetic and phenotypic features; yet accurate classification and particularly exclusion of chronic myeloid leukemia (CML) is essential from both therapeutic and prognostic point of views. The WHO classification of hematopoietic neoplasms relies on genetic features to distinguish between Philadelphia positive (CML) and Philadelphia negative MPN. CML is a stereotypic disease with almost always straight forward diagnosis in vast majority of patients. In a few cases, atypical clinical or morphologic manifestations may obscure or delay the diagnosis. Typical clinical features of classic CML include splenomegaly, which is almost always present and may be massive, and pallor from associated anemia. The peripheral blood smear (PB) smear in CML is usually diagnostic as it consistently shows leukocytosis [ranges, 12,000$\left.1,000,000 / \mu \mathrm{L}\left(12-1,000 \times 10^{9} / \mathrm{L}\right)\right]$ owing to neutrophils in different stages of maturation $[1,2]$.

Bone marrow (BM) sections are usually hypercellular owing to granulocytic proliferation with markedly increased myeloid/erythroid $(\mathrm{M} / \mathrm{E})$ ratio, erythroid islands are usually reduced in number and in size. Megakaryocytes commonly exhibit distinguishing morphologic features as they are smaller than normal with hypolobated nuclei (“dwarf megakaryocytes") [3,4].
Average platelet count in $\mathrm{CML}$ at diagnosis ranges from normal to less than $1,000 \times 10^{3} / \mu \mathrm{L}$ [1]. Although thrombocytosis is a relatively common presenting feature, it rarely exceeds $>1000 \times 10^{9} / \mathrm{L}$.

CML can rarely present in ET-like picture with no initial features to raise the specter of CML, specifically, no splenomegaly, no leukocytosis, and no immature myeloid cells on peripheral smear.

Here we describe a rare case of CML case with a classical Philadelphia translocation and common $B C R-A B L 1$ fusion transcript but an unusual clinical and pathological presentation which illustrates the underlying genetic heterogeneity of MPNs. The aim of this report is to emphasize on the importance of excluding CML by testing for BCR/ABL-1 in all cases with features of myeloproliferative neoplasms in order to avoid delayed management and adverse outcome. Early initiation of a specific inhibitor of the $B C R / A B L$ tyrosine kinase in these patients probably could have more readily controlled blood counts, prevented thrombotic complications, and spared drug toxicities.

\section{Case Presentation}

A 46 years old gentleman, heavy smoker, known case of type II Diabetes Mellitus on Insulin, presented with complaint of intermittent

*Corresponding author: Dina S Soliman, Associate Consultant Hematopathologist, Department of Laboratory Medicine and Pathology, National Center for Cance Care and Research, Hamad Medical Corporation, Doha-Qatar and Adjunct Assistant Professor, Department of Clinical Pathology, Weill Cornell Qatar, DohaQatar, National Cancer Institute, Cairo P.O. 3050, Egypt, Tel: 00974-33020784; E-mail: dsoliman@hamad.qa

Received April 29, 2019; Accepted May 06, 2019; Published May 15, 2019

Citation: Soliman DS, Abdulla MA, Sabbagh AA, Akiki S, Ibrahim F, et al. (2019) BCR/ABL-1-Positive Myeloproliferative Neoplasm Presenting with Isolated Remarkable Thrombocytosis with Atypical Clinicopathological Features: Discussion from Management Point of View. J Blood Lymph 9: 243.

Copyright: ( 2019 Soliman DS, et al. This is an open-access article distributed under the terms of the Creative Commons Attribution License, which permits unrestricted use, distribution, and reproduction in any medium, provided the original author and source are credited. 
Citation: Soliman DS, Abdulla MA, Sabbagh AA, Akiki S, Ibrahim F, et al. (2019) BCR/ABL-1-Positive Myeloproliferative Neoplasm Presenting with Isolated Remarkable Thrombocytosis with Atypical Clinicopathological Features: Discussion from Management Point of View. J Blood Lymph 9: 243.

chest pain on moderate exertion, associated with dyspnea. Physical examination was unremarkable (no palpable hepatosplenomegaly and no lymphadenopathy). No other cardiovascular or systemic symptoms. No recent surgeries, trauma and no history of blood loss. His initial complete blood count (CBC): white blood cells (WBCs) $6.7 \times 10^{3} / \mu \mathrm{L}(4.0-10.0)$; hemoglobin $(\mathrm{Hb}) 11.7 \mathrm{gm} / \mathrm{dL}(13.0-17.0)$ with extreme thrombocytosis platelets (PLts) $2.065 \times 10^{3} / \mu \mathrm{L}(150$ 400). Complete metabolic panel within normal apart from high glucose. Electrocardiogram (ECG) showed normal sinus rhythm was no ischemic changes. Echocardiography revealed normal left ventricular systolic function with ejection fraction $55-60 \%$ and no regional wall motion abnormalities. Abdominal ultrasound showed no hepatosplenomegaly or abdominal masses. Because of extreme unexplained thrombocytosis, work-up to exclude clinically suspected essential thrombocythaemia (ET).

Peripheral blood (PB) smear showed extreme thrombocytosis with mild anemia and marked basophilia (10\%). No leukocytosis, no shift to left and no circulating blasts seen (Figure 1A and 1B).

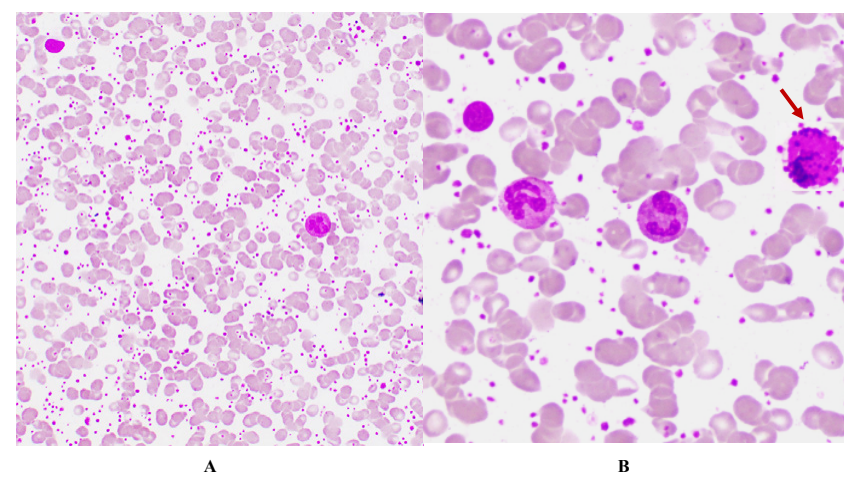

Figure 1: Peripheral blood smear (P.S) shows extreme thrombocytosis. No leukocytosis $(500 \times)$. (A) Basophilia (black arrow); (B) No shift to left $(1000 \times)$.
Bone marrow $(\mathrm{BM})$ aspirate smear showed trilineage hematopoiesis (Figure 2A) with moderate erythroid hyperplasia with increased early forms and some megaloblastoid changes (Figure 2B).

Megakaryocytes are markedly increased; showing anisocytosis; mostly represented by small hypolobated forms (micromegakaryocytes) with some atypical megakaryocytes showing abnormal nucleocytoplasmic ratio and abnormal nuclear lobulation/chromatism (Figure 2C).

Granulopoiesis was mildly suppressed with decreased myeloid/ erythroid $(\mathrm{M} / \mathrm{E})$ ratio at $0.9: 1$ with orderly maturation, increased basophils (3\%) and increased blasts (5\%) (Figure 2D).

BM biopsy was normocellular for age $(\sim 50-60 \%)$ with prominent erythropoiesis, relatively decreased granulopoiesis and marked megakaryocytic hyperplasia, mostly small hypolobated forms with some small clusters and no prominent atypia noted (Figure 3).

CD34 immunostain highlighted increased vasculature with intrasinusoidal hematopoiesis and increased CD34-positive blasts (roughly estimated by 7-10\% with few adjacent cells) (Figure 3G). No significant increase in reticulin fibers. B-cells.

There is an atypical lymphoid aggregate composed of mixed $\mathrm{T}$ and

Based on peripheral blood counts and BM findings, ET was preferentially considered over other MPNs. However, JAK2 V617F mutation, JAK exon 12-15 mutation, and CALR exon 9 mutations, were reported as negative. Surprisingly, karyotype analysis showed the Philadelphia chromosome without any additional cytogenetic abnormalities 46,XY,t(9;22)(q34;q11.2) [13]/46,XY [7].

Subsequently, $B C R / A B L 1$ fluorescence in situ hybridization (FISH) analysis confirmed a $B C R-A B L 1$ gene fusion and Reverse transcriptase- polymerase chain reaction (RT-PCR) analysis for $B C R /$ $A B L 1$ rearrangement revealed a common e13a2 breakpoint. A diagnosis
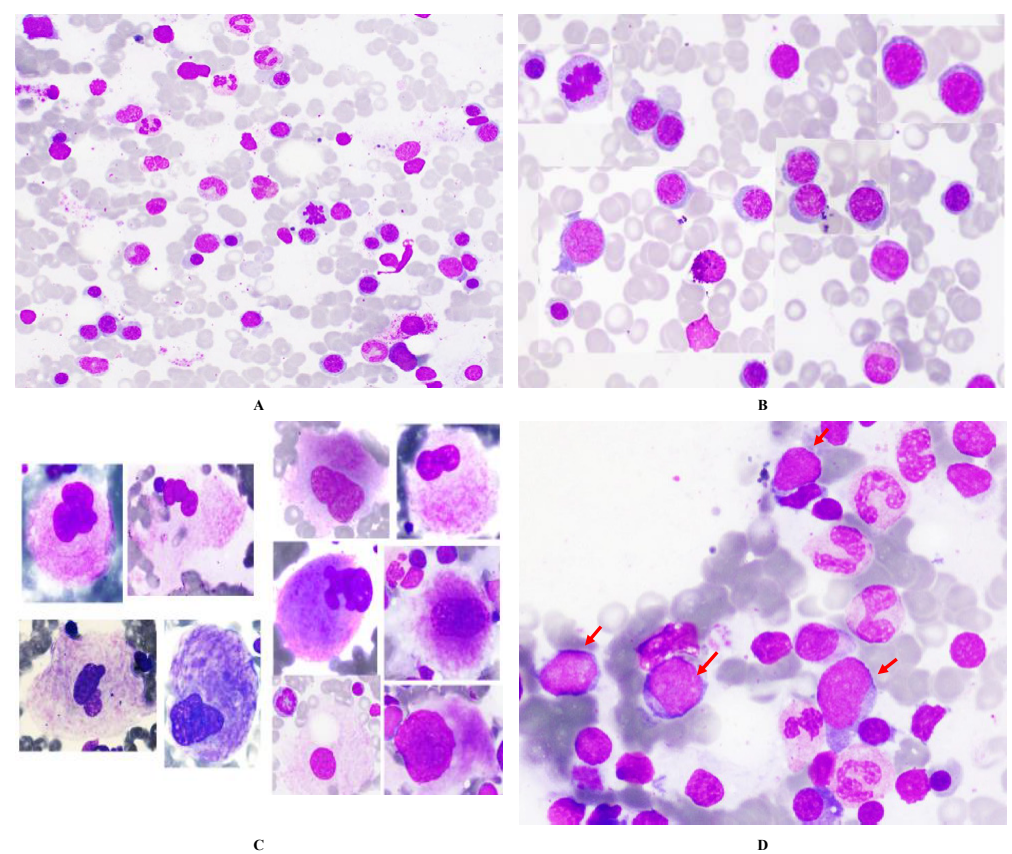

Figure 2: (A) BM aspirate smear (500 × ) shows trilineage hematopoiesis; (B) Erythroid hyperplasia; (C) Marked megakaryocytic hyperplasia with many dwarf forms (micromegakaryocytes) and (D) Increased blasts. 
Citation: Soliman DS, Abdulla MA, Sabbagh AA, Akiki S, Ibrahim F, et al. (2019) BCR/ABL-1-Positive Myeloproliferative Neoplasm Presenting with Isolated Remarkable Thrombocytosis with Atypical Clinicopathological Features: Discussion from Management Point of View. J Blood Lymph 9: 243.

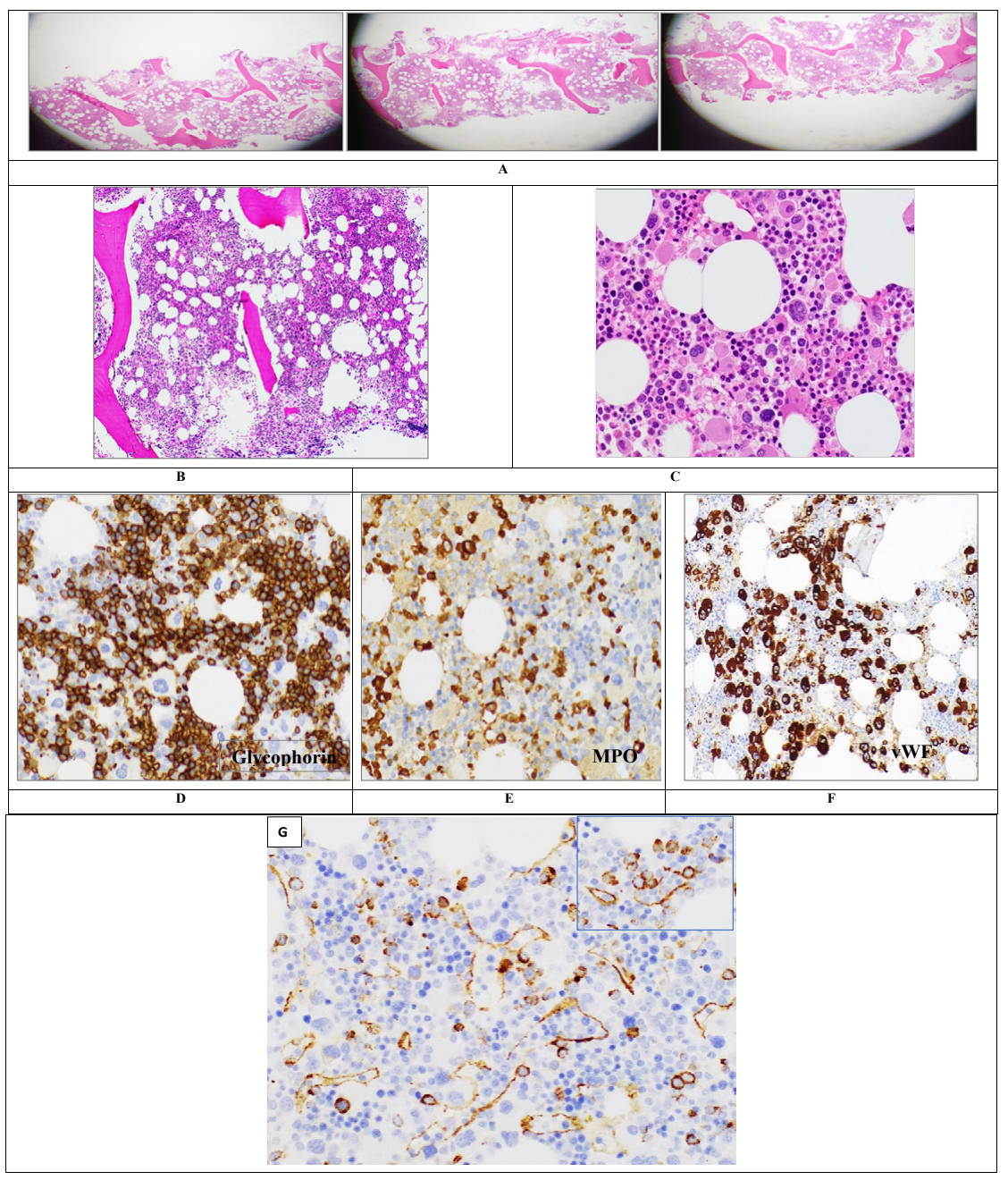

Figure 3: (A) Bone marrow biopsy (H\&E) 40 ×; (B) BM shows normal cellularity ( 50-60\%); (C) With prominent erythropoiesis; (D) Glycophorin immunostain highlighted erythroid hyperplasia; (E). MPO immunostain shows relatively decreased granulopoiesis; (F) vWF: immunostain highlights marked megakaryocytic hyperplasia, mostly small hypolobated forms with some small clusters; (G). CD34 immunostain highlighted increased vasculature with intrasinusoidal hematopoiesis and increased CD34-positive blasts $(\sim 7-10 \%)$ with tiny clusters (upper right corner insert.

of CML, chronic phase associated with extreme thrombocytosis was reported. In view of marked thrombocytosis with increased CD34 immunostain positivity, these findings were considered as presumptive evidence of impending acceleration.

During the initial diagnostic period, the patient was started on Hydroxyura for more than one month; however thrombocytosis was refractory with no significant response in counts (Figure 4A).

Following the diagnosis of CML, Tyrosine kinas inhibitor (TKI) therapy (Dasatinib $70 \mathrm{mg}$ twice daily) was started and the platelets dropped dramatically (Figure 4B). Follow-up at 3 months interval showed complete haematological response with normalization of platelets counts and the patient achieved complete cytogenetic response at 6 months. Dasatinib dose was reduced to $70 \mathrm{mg}$ daily and $B C R-A B L 1$ transcript levels were monitored throughout treatment following the ELN expert recommendations [5]. The patient has sustained a major molecular response for more than 2 years after diagnosis.

\section{Discussion}

Since 2001 WHO diagnostic criteria for ET mandate that $B C R$ -
ABL1 should be negative to exclude CML diagnosis (3). But lack of specific guidance for rare $\mathrm{Ph}+$ cases and atypical presentations mean opportunities to make an accurate diagnosis can be missed affecting treatment.

\section{Unusual presentation in this case}

The case presented with quite unusual pathologic and clinical findings as CML diagnosis was obscured and totally unexpected except after the cytogenetics result. Clinically, the patient was asymptomatic with no splenomegaly that is reported in the great majority of CML patients. Pathologically, absence of neutrophilic leukocytosis, shift to left together with absence of bone marrow hypercellularity. An additional unusual finding in this case is the presence of unexplained erythroid hyperplasia with decreased $\mathrm{M} / \mathrm{E}$ ratio, which is not reported in previous similar cases.

The overall findings were more convincing of ET. The dwarf megakaryocytes with almost absent large hyperlobulated forms together with marked basophilia were the only morphologic keys to CML. 
Citation: Soliman DS, Abdulla MA, Sabbagh AA, Akiki S, Ibrahim F, et al. (2019) BCR/ABL-1-Positive Myeloproliferative Neoplasm Presenting with Isolated Remarkable Thrombocytosis with Atypical Clinicopathological Features: Discussion from Management Point of View. J Blood Lymph 9: 243.

Page 4 of 6

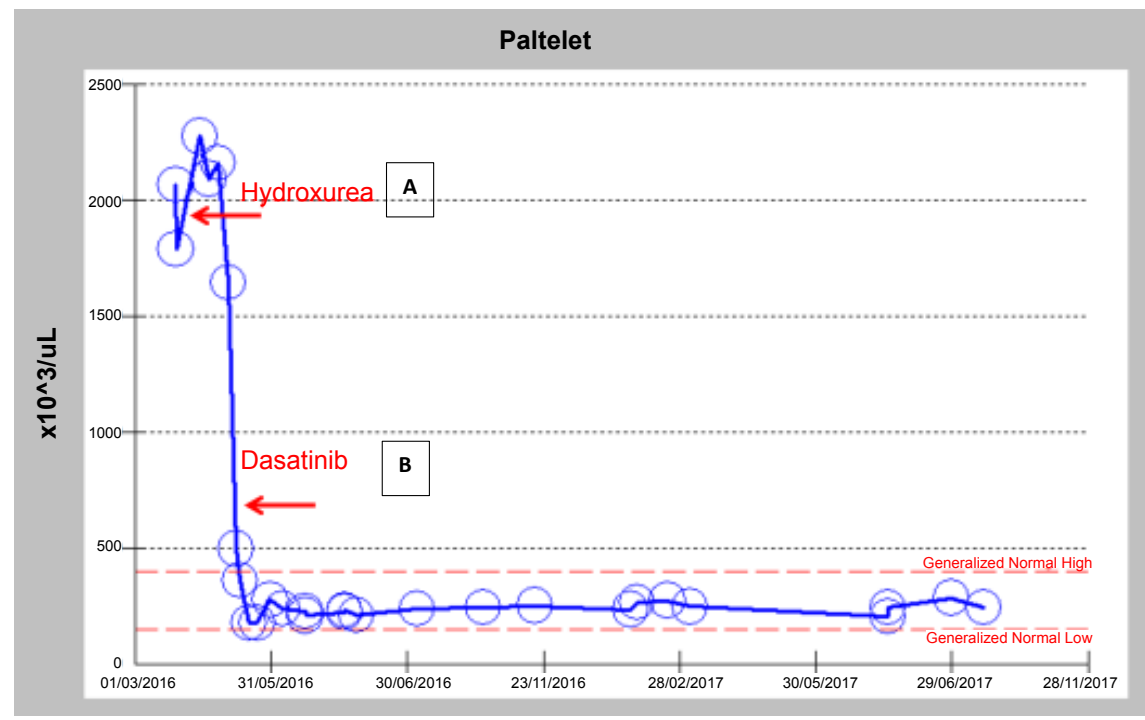

Figure 4: Platelets count response after (A) Hydroxyurea and (B) Dasatinib.

CML was a very remote possibility that was not suspected although the case was examined by three experienced hematopathologists and would definitely be missed if screening for Philadelphia was not performed. In our lab we follow WHO recommendations to perform $B C R / A B L-1$ routinely in any case with myeloproliferation. In view of marked thrombocytosis and increased CD34 positivity (appreciated in biopsy), accelerated phase of CML was suggested.

\section{Typical CML with extreme thrombocytosis}

Thrombocytosis above $2,000,000 / \mu \mathrm{L}$ is extremely rare in $\mathrm{CML}$ unless the patient is splenectomized. Rare case reports with classic CML presented with extreme thrombocytosis, [6-9] and those cases are often associated with the e19a2 BCR-ABL1 transcript type [7]. These exceptional cases have otherwise typical clinical and pathological features of CML and although platelets count exceeds $1000 \times 10^{9} / \mathrm{L}$, hemorrhagic or thromboembolic complications is far less common than ET patients who are associated with similar degree of thrombocytosis.

\section{BCR/ABL-1 testing delayed or ignored}

Upon review of literature we found that many of the patients who had this presentation had suffered from delayed management as they were misdiagnosed as ET and managed accordingly which had led to disease progression, vascular complications and transformation into accelerated or blast phases [9-12]. Rice and Popat [10] had reported two women presented with findings typical of ET with severe thromboembolic complications and absolutely no initial features raising the possibility of CML. Philadelphia chromosome testing was not performed until several years after presentation when the blood picture changed into accelerated phase CML. In the same context, some authors had suggested that isolated thrombocytosis might be an initial presentation of CML that present in a way very much mimicking to ET in all aspects [10]. Of note, in our case we had features of progressive disease evidenced by increased blasts rather than early stage of CML.

\section{BCR-ABL-positive thrombocythaemia/ET}

The term "Ph/BCR-ABL-positive thrombocythaemia /essential thrombocythameia" was used in the literature by some authors to categorise these patients. This misnomer was repeatedly used not only in old reports but also in some recent articles after release of World Health Organization classification of hematopoietic tumors release in 2001. The authors had described cases with isolated thrombocytosis in absence of leukocytosis as a distinct disease entity that has female predilection with no splenomegaly and poor prognosis. Of note, these patients were not tested for $\mathrm{Ph} / B C R-A B L-1$ at their initial presentation and managed as ET and were all refractory to therapy or show high tendency of transformation, progression to myelofibrosis and blast crisis after few to several years [11,13-17].

\section{Possibility of concurrent mutations and investigations performed}

The possibility that some atypical manifestations may be due to specific genetic lesions present concurrently with the $B C R-A B L 1$ fusion gene should also be considered. A detailed genetic analysis to look for clonal drivers may be warranted in these cases. Recently, a number of reports have described the coexistence of the JAK2V617F mutation in patients with CML, $B C R-A B L 1+$. In some cases, the mutated JAK2 was detected after treatment of CML with TKI $[18,19]$ but retrospective analyses of the initial specimen in those cases demonstrated that the mutated JAK2 was present at the time of the initial diagnosis of CML. In our case JAK-2 was performed initially at diagnosis and retested after treatment of CML and found to be negative. In addition, Next generation sequence (NGS) performed to look for other clonal markers associated with MPN but no additional variants identified [20].

\section{Literature review of similar cases}

Less than 20 cases had been reported in the English literature for $B C R / A B L-1$ positive CML presenting in ET like picture. Table 1 includes 13 cases who presented with isolated thrombocytosis and at the same time lacking all other classic features of CML (no leukocytosis and no shift to left). Unlike what was previously reported, we found males and females are equally affected (M/F: 1:1). Except for one case, no anemia was reported within this group. These cases usually present with extreme thrombocytosis, above one million in 9 out of 13 cases.

Interestingly, almost all reported cases in this context had classic $B C R / A B L$ with $\mathrm{p} 210 \mathrm{~b} 3 / \mathrm{a} 2$ break point. No concurrent JAK-2 mutation was reported in any of these cases. 
Citation: Soliman DS, Abdulla MA, Sabbagh AA, Akiki S, Ibrahim F, et al. (2019) BCR/ABL-1-Positive Myeloproliferative Neoplasm Presenting with Isolated Remarkable Thrombocytosis with Atypical Clinicopathological Features: Discussion from Management Point of View. J Blood Lymph 9: 243.

Page 5 of 6

\begin{tabular}{|c|c|c|c|c|c|c|c|c|c|c|c|}
\hline Reference & Age/Gender & $\begin{array}{l}\mathrm{Hb} \\
(\mathrm{g} / \mathrm{dL})\end{array}$ & PLT $\times 10^{9} / \mathrm{L}$ & WCs $\times 10^{3} / \mathrm{L}$ & $\begin{array}{l}\text { Shift to } \\
\text { left }\end{array}$ & $\begin{array}{l}\text { BM Cellularity, } \\
\text { M/E }\end{array}$ & Megs & Spleen & Symptoms & Treatment & Response \\
\hline Ebrahem [6] & $39 / F$ & NA & 2500 & 10 & NA & N/P & N/P & N/P & CAD & Dasatinib & OR \\
\hline \multirow[t]{2}{*}{ Rice [10] } & $27 / F$ & 14 & 1800 & 8 & N/P & N/P & N/P & No (E) & Miscarriage & \multicolumn{2}{|c|}{$\begin{array}{l}\text { Hydroxuyrea, Anagrelide: } \\
\text { Refractory, MI, PE and frank CML } \\
\text { Imatinib + then Allo SCT }\end{array}$} \\
\hline & $42 / F$ & NL & 700 & $\mathrm{NI}$ & N/P & N/P & N/P & No (E.) & MI & \multicolumn{2}{|c|}{$\begin{array}{l}\text { Hydroxuyrea } \\
\text { Imatinib + then Allo SCT }\end{array}$} \\
\hline Breccia [12] & $43 / \mathrm{M}$ & 14 & 2000 & 3 & No & N/P & N/P & N/P & None§ & \multicolumn{2}{|c|}{$\begin{array}{l}\text { Hydroxyurea: Refractory } \\
\text { Imatinib: OR }\end{array}$} \\
\hline Fadilah [15] & $35 / \mathrm{M}$ & 13 & 2500 & 14 & No & Hyper, N & Pleomorphic & No & & \multicolumn{2}{|c|}{$\begin{array}{l}\text { Hydroxurea: Controlled for one } \\
\text { year } \\
\text { Developed CML-blast phase }\end{array}$} \\
\hline Michiels [16] ${ }^{*}$ & $66 / F$ & 12 & 584 & 4.3 & No (US) & Nor,H & Small & No & None§ & \multicolumn{2}{|c|}{ Hydroxyurea: Controlled } \\
\hline Girodon [17] & $52 / \mathrm{M}$ & 13 & 672 & 7.9 & No & Hyper,N & Small & No & None§ & Imatinib & OR \\
\hline Huho [18] & 9/M & 13 & 2500 & 8 & No & $\mathrm{N}, \mathrm{N}$ & ND & No & $\begin{array}{l}\text { Cough \& } \\
\text { fatigue }\end{array}$ & Dasatinib & \\
\hline Young Jae, [21] & $21 / F$ & 10 & 3700 & 10 & No & Hyper,High & small & No & $\begin{array}{l}\text { Abdominal } \\
\text { pain }\end{array}$ & \multicolumn{2}{|c|}{$\begin{array}{l}\text { Hydroxyurea (14 days): } \\
\text { Refractory } \\
\text { Imatinib: achieved MMR }\end{array}$} \\
\hline \multirow[t]{3}{*}{ Mustafa [22] } & $77 / F$ & 14 & 711 & 5 & NA & $\mathrm{N}, \mathrm{N}$ & small & No (E) & CAD & Imatinib 400 mg/day & OR \\
\hline & 70/F & 13 & 1800 & 9 & NA & $\mathrm{N}, \mathrm{N}$ & ND & No (E) & CAD & Imatinib 400 mg/day & OR \\
\hline & 30/M & 16 & 1200 & 11 & NA & Hyper, N & small & No (E) & $\begin{array}{l}\text { VC Flu-like } \\
\text { illness }\end{array}$ & \multicolumn{2}{|c|}{$\begin{array}{l}\text { Refractory: Imatinib then Nilotinib } \\
\text { then Dasatinib }\end{array}$} \\
\hline Our case & $46 / \mathrm{M}$ & 14 & 2000 & 7 & No & $\mathrm{N} / \mathrm{N}$ & Small & No (US) & Chest pain & \multicolumn{2}{|l|}{ Dasatinib: OR } \\
\hline
\end{tabular}

Table 1: Presents cases reported in the literature after 2000 of CML presenting with isolated thrombocytosis. CAD: Coronary Artery Disease; OR: Optimal Response; Hyper: Hypercellular BM; N: Normal; N/P: Not Provided; VC: Vascular Complications; US: Ultrasound; E: Physical Exam; MI: Myocardial Infarction; PE: Pulmonary Embolism; Allo SCT: Allogenic Stem Cell Transplant. *Cases $1 \& 3$ in this report were excluded because they had leukocytosis on initial presentation. \#Cases 1,2 \& 4 in this report were excluded because they had leukocytosis on initial presentation. §ln these cases thrombocytosis was an incidental finding during routine laboratory testing. \#diagnosed as BCR/ABL-post ET.

Vascular complications/symptoms had been frequently reported within this group particularly as a complication when TKI therapy was delayed.

\section{Conclusion}

Rare cases of CML can present in a manner absolutely typical for ET and this may briefly challenge categorization. These cases usually present with extreme thrombocytosis, hence masking CML picture.

Screening for $\mathrm{Ph}$ or BCR/ABL-1 is crucial in any atypical myeloproliferation regardless of the degree of neutrophilia or thrombocytosis. Although it is required by WHO to exclude BCR/ ABL-1 before making a diagnosis of ET, many hematologists have not been persuaded to always check cytogenetic tests when there are no other features suggesting CML. Upon literature review of similar cases, it was found that whenever $\mathrm{BCR} / \mathrm{AB}-1$ testing is missed or ignored the cases are mislabeled as ET, mismanagement led to poor response and CML acceleration. Unlike what was previously reported, we found no significant difference in disease prognosis and response to therapy in this group of patients compared to classic CML, provided TKI was started early in disease course with no delay.

\section{Declarations}

\section{Statement of ethics}

The manuscript has been approved by Medical research centre, Hamad Medical Corporation.

\section{Consent for publication}

Not applicable. No patient personal identifiers/images were included in our report. A waiver of consent form had been accepted by my institution.

\section{Conflict of interest}

"The authors have no conflicts of interest to declare."

\section{Funding sources}

No funding was received.

\section{Author Contributions}

DS: Performed hematopathologic diagnosis, major contributor in writing the manuscript including literature review. AS: Agreed with hematopathologic diagnosis and reviewed the manuscript. MA: Performed clinical diagnosis, patient's monitoring and contributed to the literature review.SA: Performed molecular genetics testing. FI: Agreed with hematopathologic diagnosis and contributed in writing the manuscript. AM: Performed clinical diagnosis, patient management, monitoring and contributed by writing the Clinical section. MY: Performed clinical diagnosis, patient monitoring and reviewed the manuscript. All authors read and approved the final manuscript.

\section{References}

1. Savage DG, Szydlo RM, Goldman JM (1997) Clinical features at diagnosis in 430 patients with chronic myeloid leukaemia seen at a referral centre over a 16-year period. Br J Haematol 96: 111-116.

2. Cotta CV, Bueso-Ramos CE (2007) New insights into the pathobiology and treatment of chronic myelogenous leukemia. Ann Diagn Pathol 11: 68-78.

3. Thiele J, Kvasnicka HM, Schmitt-Graeff A, Zirbes TK, Birnbaum F, et al. (2000) Bone marrow features and clinical findings in chronic myeloid leukemia: a comparative, multicenter immunohistological and morphometric study on 614 patients. Leuk Lymphoma 36: 295-308.

4. Buesche G, Hehlmann R, Hecker H, Heimpel H, Heinze B, et al. (2003) Marrow fibrosis, indicator of therapy failure in chronic myeloid leukemia: prospective long-term results from a randomized-controlled trial. Leukemia 17: 2444-24453.

5. Baccarani M, Deininger MW, Rosti G, Hochhaus A, Soverini S, et al. (2013) 
Citation: Soliman DS, Abdulla MA, Sabbagh AA, Akiki S, Ibrahim F, et al. (2019) BCR/ABL-1-Positive Myeloproliferative Neoplasm Presenting with Isolated Remarkable Thrombocytosis with Atypical Clinicopathological Features: Discussion from Management Point of View. J Blood Lymph 9: 243.

European LeukemiaNet recommendations for the management of chronic myeloid leukemia: 2013. Blood 122: 872-884.

6. Ebrahem R, Ahmed B, Kadhem S, Truong Q (2016) Chronic Myeloid Leukemia: A Case of Extreme Thrombocytosis Causing Syncope and Myocardial Infarction. Curēus 8: e476.

7. Langabeer SE, McCarron SL, Kelly J, Krawczyk J, McPherson S, et al. (2012) Chronic Myeloid Leukemia with e19a2 BCR-ABL1 Transcripts and Marked Thrombocytosis: The Role of Molecular Monitoring. Case Rep Hematol 2012: 1-3.

8. Yamagata K, Mitani Y,Kanda Y, Yazaki Y, Hirai H (1996) Elevated platelet count features the variant type of BCR/ABL junction in chronic myelogenous leukaemia. Br J Haematol 94: 370-372.

9. Kim SY, Jeon YL, Park TS (2012) Chronic myeloid leukemia with extreme thrombocytosis. Korean J Hematol 47: 7.

10. Rice L, Popat U (2005) Every case of essential thrombocythemia should be tested for the Philadelphia chromosome. Am J Hematol 78: 71-73

11. Michiels JJ, Berneman Z, Schroyens W, Kutti J, Swolin B, et al. (2015) Philadelphia $(\mathrm{Ph})$ chromosome-positive thrombocythemia without features of chronic myeloid leukemia in peripheral blood: Natural history and diagnostic differentiation from Ph-negative essential thrombocythemia. Ann Hematol 83: 504-512.

12. Breccia $M$, Cannella $L$, Diverio $D$, Streponi $P$, Nanni $M$, et al. (2008) Isolated thrombocytosis as first sign of chronic myeloid leukemia with e6a2 BCR/ABL fusion transcript, JAK2 negativity and complete response to imatinib. Leuk Res 32: $177-180$

13. Zafar L, Alamb F, Parveza A, Beheraa S (2017) BCR/ABL positive thrombocythemia: A diagnostic dilemma. Egypt J Intern Med 29: 83-85.

14. Kwong YL, Chiu EKW, Liang RHS, Chan V, Chan TK (1996) Essential thrombocythemia with BCR/ABL rearrangement. Cancer Genet Cytogenet 89 : 74-76.

15. Fadilah SAW, Cheong SK (2000) BCR-ABL Positive Essential Thrombocythaemia A Variant of Chronic Myelogerous Leukaemia or A Distinct Clinical Entity: A Special Case Report. Singapore Med J 41: 595-598.

16. Michiels JJ, Berneman Z, Schroyens W, Kutti J, Swolin B, et al. (2004) Philadelphia $(\mathrm{Ph})$ chromosome-positive thrombocythemia without features of chronic myeloid leukemia in peripheral blood: Natural history and diagnostic differentiation from Ph-negative essential thrombocythemia. Ann Hematol 83: 504-512.

17. Girodon F, Bailly F, Barry M, Favre B, Carli PM, et al. (2005) Philadelphia chromosome-positive thrombocythemia without features of chronic myeloid leukemia (CML) in peripheral blood. Ann Hematol 84: 409-410.

18. Huho AN, Issaq N, lacobas I, Elghetany TM, López-Terrada D, et al. (2017) A Rare Case of Pediatric Chronic Myelogenous Leukemia Presenting With Severe Thrombocytosis Without Leukocytosis. Pediatr Dev Pathol 21: 100-104.

19. Inami M, Inokuchi K, Okabe M, Kosaka F, Mitamura Y, et al. (2007) Polycythemia associated with the JAK2V617F mutation emerged during treatment of chronic myelogenous leukemia. Leukemia 21: 1103-1104.

20. Krämer A, Reiter A, Kruth J, Erben P, Hochhaus A, et al. (2007) JAK2-V617F mutation in a patient with Philadelphia chromosome-positive chronic myeloid leukemia. Lancet Oncol 8: 658-660.

21. Byun YJ, Park BB, Lee ES, Choi KS, Lee DS (2014) A case of chronic myeloid leukemia with features of essential thrombocythemia in peripheral blood and bone marrow, Blood Res 49: 127-129.

22. Yilmaz M, Guvercin B, Konca C (2016) Cases of chronic myeloid leukemia presenting with isolated thrombocytosis: Case reports and review of the literature. Int J Clin Exp Med 9: 8799-8802. 